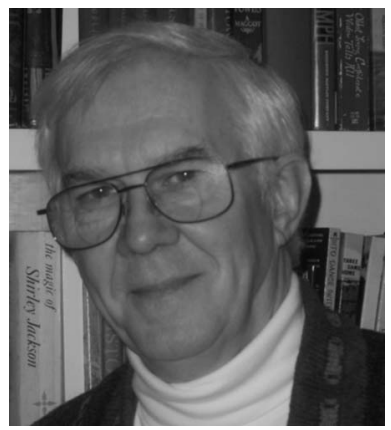

\section{Keeping Up-to-Date}

There was a time in my life as a college professor when I would take an afternoon walk to the reading room of the library. Before the trip I went through the journals on my desk: Physical Review Letters for a number of years, then Optics Letters and Applied Optics, then Optical Engineering when I joined SPIE. In the reading room, there was a stack of journals whose tables of contents (ToCs) I skimmed. When something captured my attention, I'd flip to the article to see if I wanted to copy it to read later. When I finished with those journals, I made my way to the stacks to check more specialized journals on laser Raman spectroscopy.

It was a revelation when one of my colleagues showed me a new publication, Current Contents. It was a compilation of the ToCs for a wide range of science journals. While it didn't do away with the stroll to the library, Current Contents made it easier to do the initial scan of new issues of journals. It was the beginning of a change in the information-gathering process that now includes online searches and RSS alerts.

A major benefit of SPIE membership is a subscription to one of the society's journals. These journals are now delivered online, rather than in a print format, to keep the cost of membership reasonable and as an acknowledgement of the fact that few researchers use paper copies of journals and papers anymore. However, when the electronic format was adopted, some members either didn't activate their online journal or didn't notice the request to do so in their membership materials. Now, SPIE sends new members periodic reminders about this benefit. They are also sent an e-mail alert each month listing the ToC for the journal so members are reminded to take advantage of their SPIE journal subscription.

Aside from this subscription, how can you keep up-todate with other information published by SPIE? It would be a daunting task were it not for an assortment of alerts that you can establish to fit your research interests. All of them are accessible through the SPIE Digital Library (http://SPIEDigitalLibrary.org).

First, you can get e-mail alerts for papers published in any or all of the SPIE journals, as well as those published in the Proceedings in seven topical areas. Start on the
SPIE Digital Library homepage and click the "My E-mail Alerts" link at the bottom of the yellow band that runs across the top of the page. You can then check the e-mail alerts you would like to receive. They arrive in the form of a ToC of the journal or proceedings topics that you select. They are available in HTML format, which gives you live links, or as ASCII text. Additional information on e-mail alerts can be found via a link at the end of the first paragraph of the E-mail Alerts page.

Although these e-mails list every single paper in that issue of the journal, there is something to be said for this type of alert. Just like the trips to the reading room, you get a list of papers that describe progress over a wide range of topics. This is particularly true for Optical Engineering, and provides serendipity in your searches.

But if you need to restrict your searches to a research area that you are working in, you may want to use RSS alerting. RSS, which stands for "Really Simple Syndication," allows you to monitor many sites and alerts you within a newsreader application or a browser that new material in your research area has been published. The best introduction to RSS has been offered by the BBC (http://news.bbc.co.uk/2/hi/help/3223484.stm). It includes links to the most popular newsreaders for Windows, Macintosh, and various browsers. As a Mac person, I use NetNewsWire for my newsreader.

To access RSS links, click the Journals tab at the top of the SPIE Digital Library home page. This takes you to a Web page with RSS links to the current issue, the current volume, or a listing of all available volumes for any of the SPIE journals. Each day as a new paper is published, a link with its title, authors, and the first two lines of the abstract is sent to your newsreader. When you click on the newsreader item, a Web page devoted to this paper is opened in the newsreader or a separate browser. It contains the complete abstract, the references cited in the paper, and links to download the paper. Aside from a feature that hides the paper's keywords, it is a beautifully designed format for assessing and accessing a paper.

If you don't need alerts on all the papers in Optical Engineering, you can set up an RSS feed for one of seven categories of related topical areas. For all the other journals only the full issue alerts are available. However, if 
you prefer a narrower set of alerts, you can devise your own with as much precision as you wish. In the upper left-hand corner of the SPIE Digital Library Journals page, there is a search box that is the entry to a powerful search engine and to exquisitely targeted RSS feeds.

To better appreciate its power, it is best to click on the "Advanced Search" link just below the Search button. You will see a highly flexible search that lets you specify a search in a range of search fields, the Boolean logic to be used, and the journals to be searched. You can include all SPIE papers and Proceedings.

For example, if I wanted to see the papers on ultrafast optics in Optical Engineering, I can type in "ultrafast" and select "Full Bibliographic Record" and "optics" with the same search field. This generates 91 papers. I can refine this to fewer papers by adding an additional term. (Tips for constructing search strings and a link to more examples are given below the search field.)

The most useful aspect of this exercise is found at the top of my list of search results. There the search is described: "You were searching for: ((ultrafast) < and $>$ (optics))." Most important, next to this description is an RSS feed icon. When I click on this, an RSS feed is generated and, in my case, NetNewsWire becomes active and offers to subscribe to the feed. Then, anytime Optical Engineering publishes an ultrafast optics paper, an item will pop up in my newsreader. When I select the item inside the newsreader, it opens up the Web page for the paper. This can be extended to all SPIE papers by returning to the SPIE Digital Library and changing the selections.

So there is no need to stroll to the library reading room any more. But in these hectic times, it probably would be difficult anyway because of all of the campus construction, in addition to busy schedules. This assumes there are reading rooms anymore. I haven't been in one in years and they have probably been replaced by computer carrels.
Donald C. O'Shea Editor 